\title{
Evaluating IoT based passive water catchment monitoring system data acquisition and analysis
}

\author{
Muhammad Aznil Ab Aziz, M. F. Abas, Mohamad Khairul Anwar Abu Bashri, N. Md. Saad, \\ M. H. Ariff \\ Faculty of Electrical and Electronics Engineering, Universiti Malaysia Pahang, Malaysia
}

\begin{tabular}{l}
\hline \hline Article Info \\
\hline Article history: \\
Received Mar 29, 2019 \\
Revised May 19, 2019 \\
Accepted Jun 28, 2019 \\
\hline
\end{tabular}

Keywords:

IoT

Water catchment monitoring

Water mapping

Water quality

\begin{abstract}
Water quality is the main aspect to determine the quality of aquatic systems. Poor water quality will pose a health risk for people and ecosystems. The old methods such as collecting samples of water manually and testing and analysing at lab will cause the time consuming, wastage of man power and not economical. A system is needed to provide a real-time data for environmental protection and tracking pollution sources. This paper aims to describe on how to monitor water quality continuously through IoT platform. Water Quality Catchment Monitoring System was introduced to check and monitor water quality continuously. It's features five sensors which are temperature sensor, light intensity sensor, $\mathrm{pH}$ sensor, GPS tracker and Inertia Movement Unit (IMU). IMU is a new feature in the system where the direction of $\mathrm{x}$ and $\mathrm{y}$ is determined for planning and find out where a water quality problem exists by determining the flow of water. The system uses an internet wireless connection using the ESP8266 Wi-Fi Shield Module as a connection between Arduino Mega2560 and laptop. ThingSpeak application acts as an IoT platform used for real-time data monitoring.
\end{abstract}

Copyright $@ 2019$ Institute of Advanced Engineering and Science. All rights reserved.

\section{Corresponding Author:}

M. F. Abas,

Faculty of Electrical and Electronics Engineering,

Universiti Malaysia Pahang,

26600, Pekan, Pahang, Malaysia.

Email: mfadhil@ump.edu.my

\section{INTRODUCTION}

Water quality is one of the topics that is always sought. Water is the basic component of human beings and other living organisms, therefore good quality of water is a must. In obtaining water quality, many developments have been made to reach the watershed quality. N. Vijayakumar et. al. has discussed on how to develop a low-cost system for real time monitoring of water quality in Internet of Things (IoT) continuously [1]. Five parameters were measured which is temperature, $\mathrm{pH}$, turbidity, conductivity and dis-solved oxygen (DO). A microcontroller used for the system is raspberry Pi B+ and the data can be view on the cloud using specific IP address.

Other water quality measurement system has also been discussed by Brinda Das et. al. [2]. They used IoT platform to monitor water quality in real time. The system was designed to be more effective action, economical, accurate, and required less man-power. The users can access data via ThingSpeak that monitor three parameters which are $\mathrm{pH}$, conductivity and temperature. Paper [3] authored by Ch. Sowmya et. al. also monitors the three parameters but uses ZigBee Mesh network for convaying the result to users. Nahla Abdul Jalil Salih et. al [4] proposed a system to moniter $\mathrm{pH}$ and temperature for fish pond's water. A microcontroller used for the system is Arduino UNO and the data can be view on handphone via Bluetooth communication. The system has successfully been tested. 
C. Z. Myint et. al. [5] proposed a new smart water quality monitoring system that can reduce the power consumption with five criteria that have been measured which are $\mathrm{pH}$, water level, turbidity, carbon dioxide and water temperature. They used Cyclone V DE1-SoC FPGA board that receive the data collected by sensor nodes. A smart water quality monitoring system for Fiji has been introduced by A.N.Prasad et. al. [6]. The used IoT and remote sensing technology in the system. Four different water sources were tested with four condition of water quality which are $\mathrm{pH}$, conductivity, temperature and oxidation-reduction potential (ORP) within 12 hours at hourly interval to test system accuracy. A.A. Pranata et. al. in [7] measures three parameters including temperature, $\mathrm{pH}$ and $\mathrm{DO}$ with ZigBee protocol for nodes communication.

In paper [8] written by T.I. Salim, they proposed to uses Online Water Quality (OWQ) with continuous data sampling with higher sampling rate in the system. Seven parameters have been measured which are dissolved gas, acidity, temperature, turbidity, conductivity, salinity, and total dissolved solid (TDS). Next, the data can be easily view and monitor via Favoriot platform in paper [9]. A. Latiff et. al. applied five sensors in the system which are $\mathrm{pH}$, temperature, ORP, DO, and electrical conductivity (EC). C.Z. Myint et. al. in another paper [10], has designed the system to reduce critical issue for water pollution. They design WSN based reconfigurable smart sensor interface for water quality monitoring system in an IoT platform. Water quality condition such as $\mathrm{pH}$, water level, turbidity, $\mathrm{CO} 2$ and water temperature have been analysed.

K. H. Kamaludin in [11] was discussed on implementation of RFID in water quality monitoring system. The purpose is to communicate into a single platform for water quality monitoring. While, C. Encinas et. al. proposed to solve the issue of aquaculture areas that lag behind the technology [12]. The systems will monitor based on wireless sensor network via IoT. The system will measure the $\mathrm{pH}$, temperature and DO of water with a benefit of low-cost, portable, modular, versatile and allows sharing information through the cloud. With an extra electrical conductivity sensor, Lambrou et. al. in their paper [13] has developed a water quality monitoring systems using PIC32 MCU with ZigBee as its communication module. Mohammad Azman Miskan et. al. in paper [14], monitors temperature and DO and relay the information via RF transceiver.

Extending water quality monitoring done by previous author, K. Raghu Sita Rama Raju et. al. in paper [15] also includes monitoring of Ammonia, Salt, Nitrate and Carbonates besides monitoring DO, pH and temperature. The system uses Raspberry pi3 with IoT connection to phone but the IoT connection was not discussed in the paper. Based on the result, the hardware has successfully monitors all seven parameters. Paper [16] also designed a system to log the seven parameters but using WaspMote instead of Raspberry pi3.

Tomoaki Kageyama in [17] has developed a wireless sensor network platform. The platform as mention from the paper utilizes three sensors which is conductivity sensor, temperature sensor and illuminometer. Unfortunately, the paper does not mention the microcontroller/microprocessor used. The data obtained was relayed to Google spreadsheet via $3 \mathrm{G}$ network.

pH, Oxygen level and Turbidity was measured in the system design by Kulkarni Amruta M. et. al. in paper [18]. Utilizing ARM7 as its processor, the data obtained is relayed to the main computer via Zigbee. The data is then analyzed via MATLAB and displayed to the user using GUI created via VB 6.0. Khetre et. al. in paper [19] also uses ARM7 processor. They use the processor for water quality monitoring of temperature, turbidity, water level and salinity.

Nidal Nasser et. al. has also designed a wireless water quality monitoring system which utilizes $\mathrm{pH}$ sensor in paper [20]. The system uses multiple ZigBee as sensor nodes which will relay information from $\mathrm{pH}$ sensor to the Base Station. The Base Station will then relay the information to data center and client server via internet connection. The system also incoperates sleep scheduling mechanism in the sensor nodes to prolong its network lifetime.Component combination of LDR and LED has been used to develop a turbidity sensor in paper [21]. Intel Galileo Gen 2 was used as the systems microcontroller which was connected to ThinkSpeak via ESP82566 wifi module. The system has successfully been tested and shows good result for obtaining turbidity in flowing water.

F. R. Islam et. al. in their paper [22] has developed a system which measures pH, Conductivity, Temperature and ORP. By utilizing a controller connected to a mobile phone, the system can acquire Global Positioning System (GPS) coordinate and Global System for Mobile (GSM) communication. With this, GIS mapping of the measurement is able to be done. With an absence of OPR, He et. al. in their paper [23] utilize CC2430 MCU for its microcontroller and ZigBee as its communication module. Similarly, Rasin et. al. in paper [24] also developed water quality monitoring system for monitoring temperature, $\mathrm{pH}$ and turbidity but uses Ti based microcontroller, TI 8051.

This paper discussed the development of water quality catchment monitoring system which integrates $\mathrm{pH}$, light intensity, temperature, GPS, and IMU readings. Based on the literature done, none of them includes IMU reading. The developed system is a passive system which has no propulsion system. The system could only move by utilizing the water flow. Since the distribution of polutent is also due to water 
flow, measuring the motion of the system using IMU will also measure the water flow. With the water flow and other sensor reading acquired, it is possible to predict the source of contamination. The prediction method will be discussed in other future papers. The developed system has been tested at lake in UMP Pekan Campus, Pahang, Malaysia and leads to promising result.

\section{RESEARCH METHOD}

\subsection{Hardware development}

The Water Quality Catchment Monitoring System in this paper is an upgrade version from previous development which can be seen in paper [25]. This version includes IMU and ThinkSpeak in order to increase the capability of the system to be used to monitor mater movement. The block diagram of the system can be seen in Figure 1. The system includes pH, Light Intensity, Temperature, GPS, IMU and Wi-Fi shield. The Wi-Fi shield is use to replace XBEE from previous system. With the Wi-Fi shield, the data acquired which is the $\mathrm{pH}$, Light Intensity, Temperature, GPS, IMU and Wi-Fi shield can be access directly from ThinkSpeak from any internet connected terminal. The data was also logged into the onboard logger and analyze using MATLAB. The specification of each sensor can be seen in Table 1 . The system in Figure 1 was installed in a 3D printed casing as shown in Figure 2. The bottom of the casing is attached with four $1 / 2$ tennis ball and polystyrene sheet to improve buoyancy and stability.

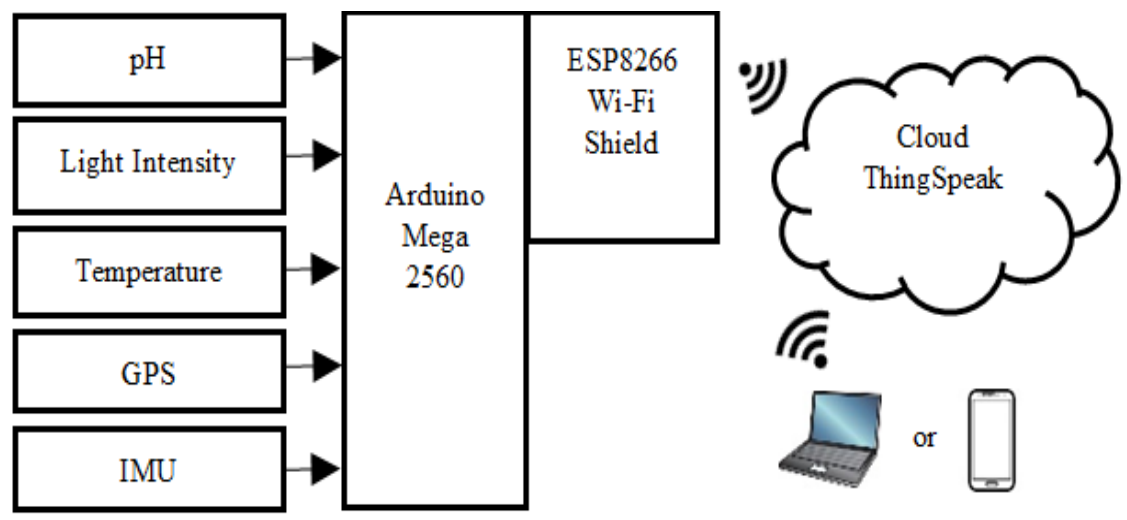

Figure 1. Block diagram

Table 1. Sensors

\begin{tabular}{cccc}
\hline No & Type & Model & Usage \\
\hline 1 & Analog pH & SEN0161 & Measuring pH \\
2 & Analog Light & GA1A12S202 & Measuring turbidity \\
3 & Temperature & DS18B20 & Measuring Temperature \\
4 & GPS & LOCOSYS LS-23060 & Coordinate Acquisition \\
5 & IMU & BNO055 & Identify water flow \\
\hline
\end{tabular}

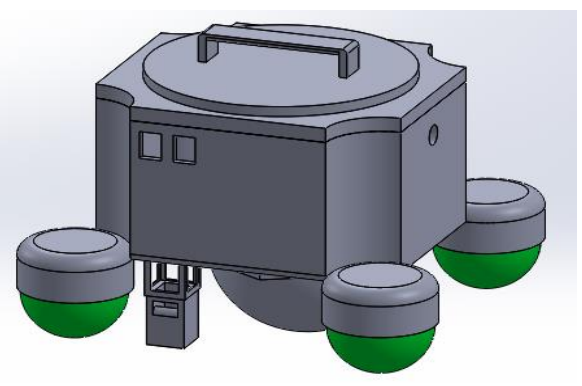

(a)

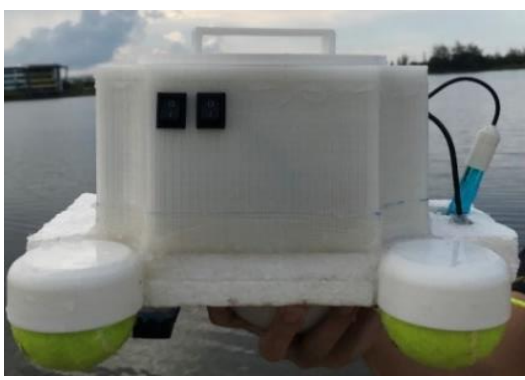

(b)

Figure 2. (a) 3D layout, (b) 3D Printed and installed 


\subsection{Test procedures and assumptions}

Testing of the system was done at UMP's lake near the library. The circumference of the lake is about $1.6 \mathrm{~km}$ which is big enough to be set as testing area. 16 sites on the lake were chosen as acquisition sites. The sites can be seen in Figure 3 and their GPS coordinate can be seen in Table 2.

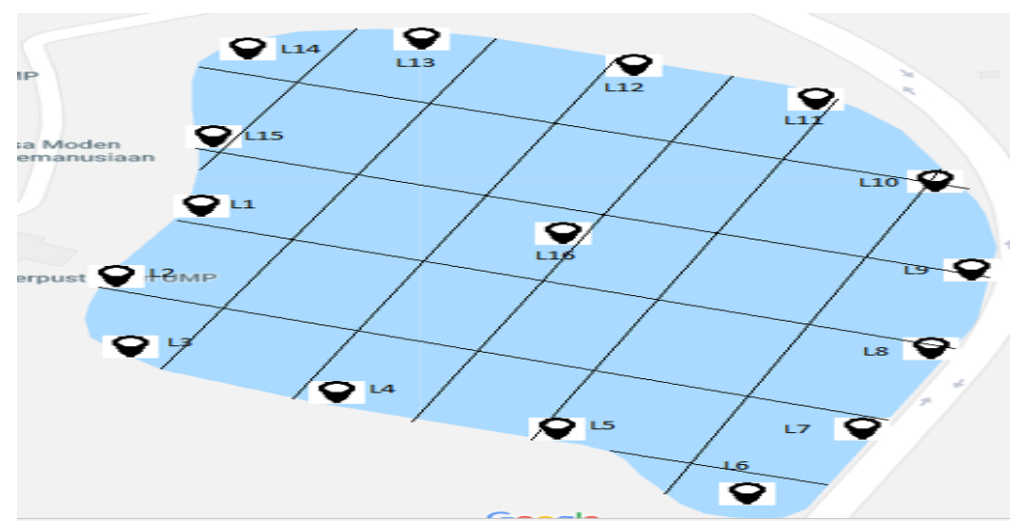

Figure 3. Testing locations (underlay map is from google map)

Table 2. Test locations coordinates (taken via onboard GPS)

\begin{tabular}{cccccc}
\hline Location & Latitude & Longitude & Location & Latitude & Longitude \\
\hline L1 & 3.543005 & 103.432457 & L9 & 3.543994 & 103.435234 \\
L2 & 3.542222 & 103.431861 & L10 & 3.544439 & 103.434654 \\
L3 & 3.541599 & 103.43264 & L11 & 3.544824 & 103.433631 \\
L4 & 3.541292 & 103.433395 & L12 & 3.544918 & 103.433189 \\
L5 & 3.540958 & 103.434051 & L13 & 3.544946 & 103.432716 \\
L6 & 3.540804 & 103.434883 & L14 & 3.544626 & 103.432266 \\
L7 & 3.542159 & 103.435577 & L15 & 3.543922 & 103.432281 \\
L8 & 3.54316 & 103.435638 & L16 & 3.542619 & 103.433998 \\
\hline
\end{tabular}

To eliminate any water ripple while taking experimental data, the system is deployed and is fixed to a rope as can be seen in Figure 4. For location L16, the system is deployed via a canoe. For location L16, the data was taken around 10 minutes after the system is set to reduce the effect of ripple due to the operation of the canoe. In real life application, the system is left free on the water without any rope. Each location is sampled for 5 minutes and took around 4 hours to complete all 16 locations. The data was taken during the afternoon and an assumption has been made that the wind does not change during the duration of the time. Fortunately, during the acquisition of data, there were no other canoes operating on the premise. For this test, the data was taken directly from the system to reduce collection time. Based on this assumption and set-up, the result and discussion can be seen in the following section.

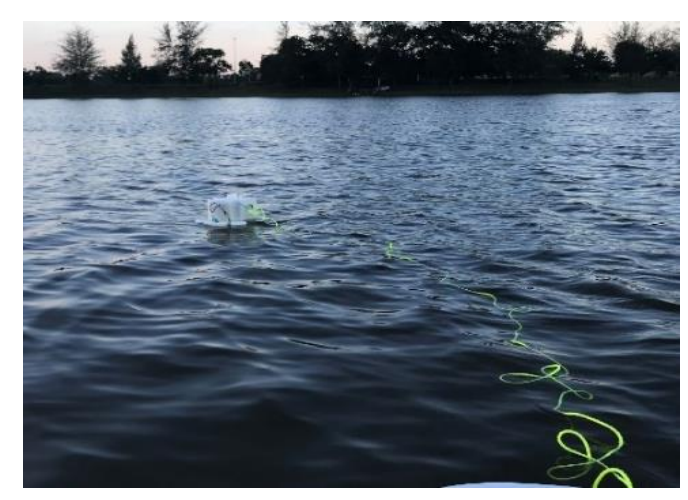

Figure 4. Collecting data 


\section{RESULTS AND ANALYSIS}

The system was implemented at UMP's lake and results were obtained. For each location, the data including temperature, $\mathrm{pH}$, light intensity and IMU were analysis by applying box-plot graph technique and plotting its mean directly on the map. The location is determined from the coordinate given by GPS Tracker in the system. 50 data samples for each location have been collected and analyze to plot in boxplot.

\subsection{Acidity}

Figure 5 shows the boxplot graph of acidity in terms of $\mathrm{pH}$ for every 16 locations. $\mathrm{pH}$ value for every locations are different from value of 5.90 until 7.23. Location 5 shows a highest $\mathrm{pH}$ value which is 7.23. The value is still in normal condition of water as the neutral water value is 7 . At location 16 , there are numerous outliers. Since the utilization of a canoe to deploy the system at location 16, the water seems to be agitated. This may be the reason for the outliers. The average value of $\mathrm{pH}$ for all locations is 6.97.

Figure 6 shows a map with its data collection point colored with the mean $\mathrm{pH}$ value of the location. The arrow shows the increase acidity of the water. Referring to Figure 6, location L5, L9 and L15 shows almost neutral water. From location L5 to L3, the acidity increased (as $\mathrm{pH}$ value decrease, acidity increased). This is similar from location L9 to L16, L9 to L12 and L15 to L3. Evidently, location L3 shows a higher acidity level compared to other locations. The center of the lake shows midpoint between the highest and lowest $\mathrm{pH}$ value of the whole lake.

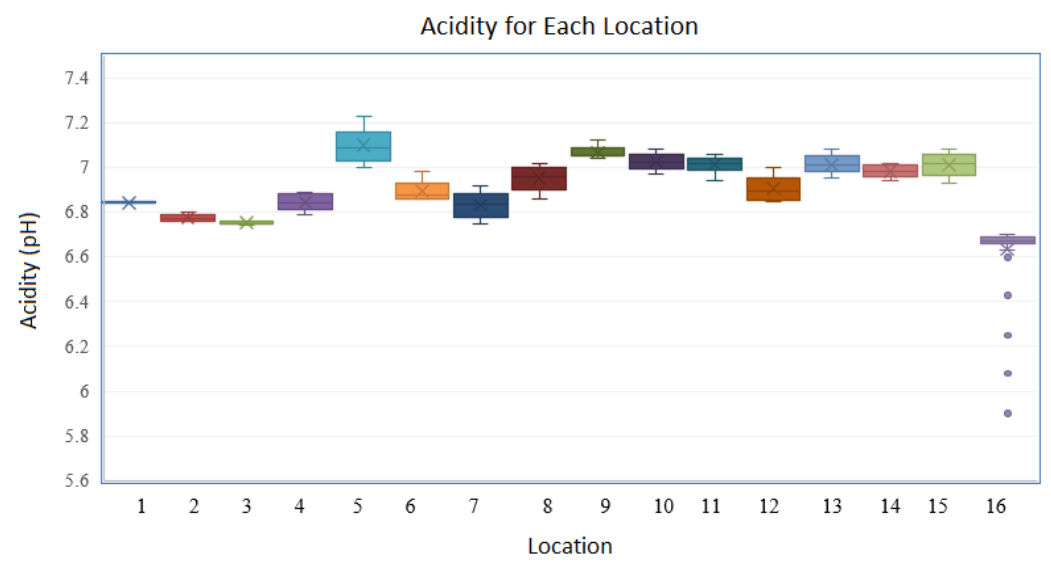

Figure 5. Acidity boxplot

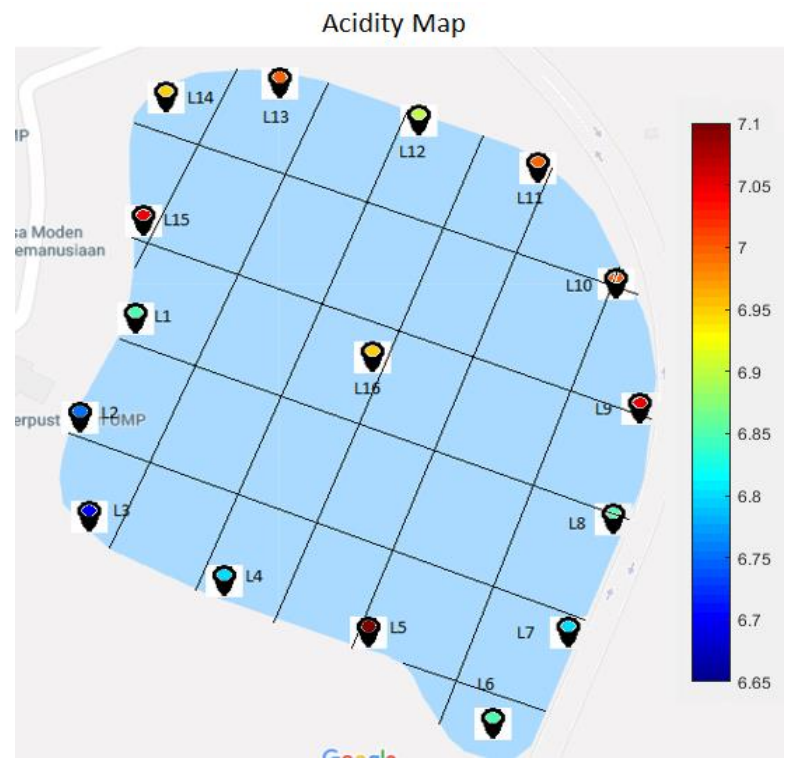

Figure 6. Acidity map 


\subsection{Temperature}

Figure 7 shows the boxplot graph of temperature for every 16 locations. The temperature sensor on the system only acquires surface temperature. The temperature values for all locations are varied from $26.0^{\circ} \mathrm{C}-33.9^{\circ} \mathrm{C}$. Location L9, L10, L13 and L14 exhibit lots of outliers. These outliers may be due to water is agitated and temperature variation from the effect of wind. Near these locations, there are no obstacles to be found. The average value of temperature for all locations is $32.67^{\circ} \mathrm{C}$.

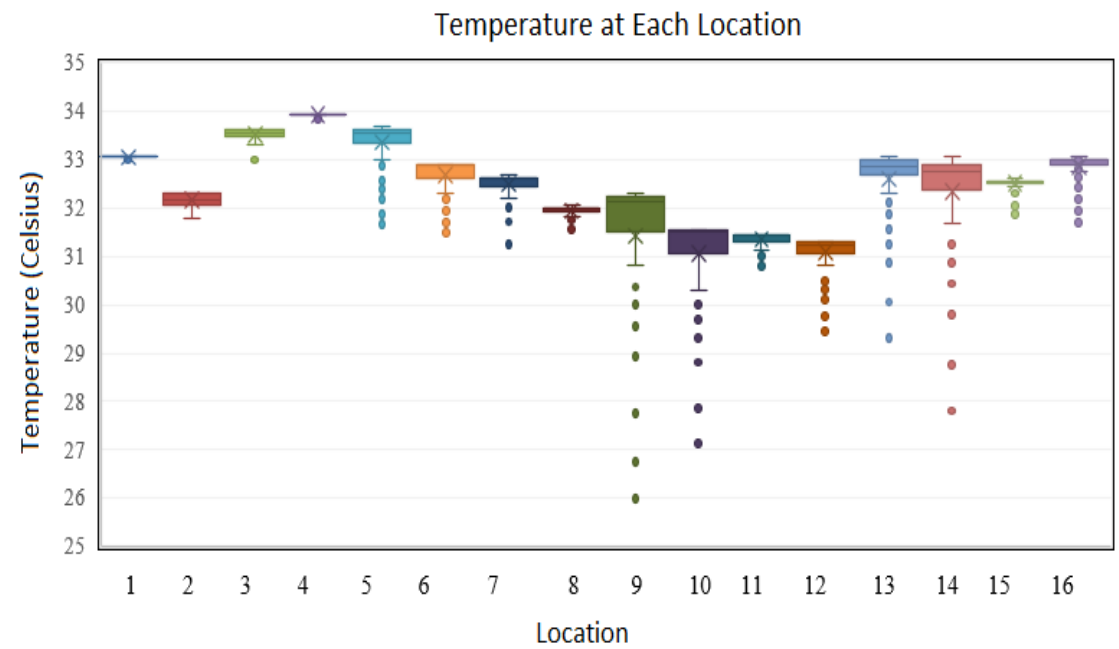

Figure 7. Temperature boxplot

Figure 8 shows a map with its data collection point colored with the mean temperature value of the location. The arrow shows the decreasing temperature of the water. Referring to Figure 8, location L4 has the highest value and the temperature decrease as the location increases and is shown by the anticlockwise arrow. The temperature also decreases as the location decreases from L4. Temperature reading at location L1, L13, L14 and L15 apparently has no distinct relationship with the other locations. The center of the lake shows midpoint between the highest and lowest temperature value of the whole lake.

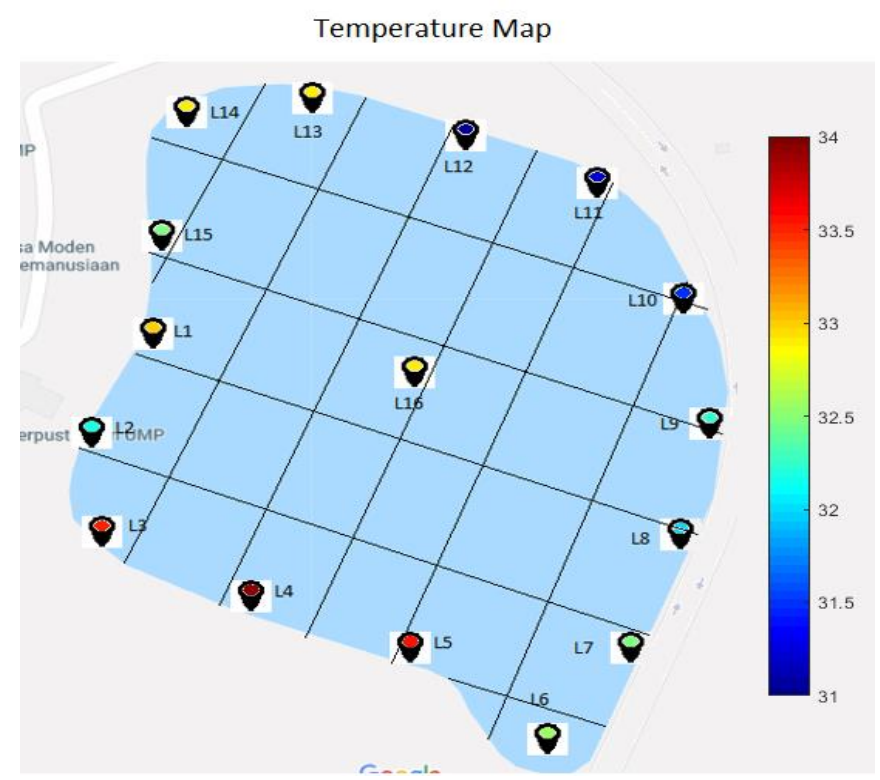

Figure 8. Temperature map 


\subsection{Light intensity}

Figure 9 shows the boxplot graph of light intensity for every 16 locations. The light intensity measured here is the light from the LED when it hits the light dependent resistor (LDR). Outside light is barred by the 3D printed casing. This method is used to measure the turbidity of the water. The higher the Lux measured by the LDR, the lower the turbidity. The average value of light intensity for all locations is 1340.32 lux. The value is varied from 438.13 lux until 4343.05 lux. Location 3, 4, 9, 10 and 11 shows the highest intensity of water which means the water at that location is clear. A lot of outliers can be seen at location L4, L9, L11 and L16. This shows that at that particular location, random agitation occurred. The random agitation may be due to the presence of aquatic life swimming across that area.

Figure 10 shows a map with its data collection point colored with the mean lux value of the location. The arrow shows the increasing light intensity of the water. Referring to Figure 10, location L2, L8, L13, L14 and L15 has a light intensity value less than 1000 lux. This shows that, this area has high turbidity. Observation at this location shows that numerous fish has been sited. Apparently this location is famous among the campus citizen for fish feeding. The highest value iand the temperature decrease as the location increases and is shown by the anticlockwise arrow. The temperature also decreases as the location decreases from L4. Temperature reading at location L1, L13, L14 and L15 apparently has no distinct relationship with the other locations. The center of the lake shows mid-point between the highest and lowest temperature value of the whole lake.

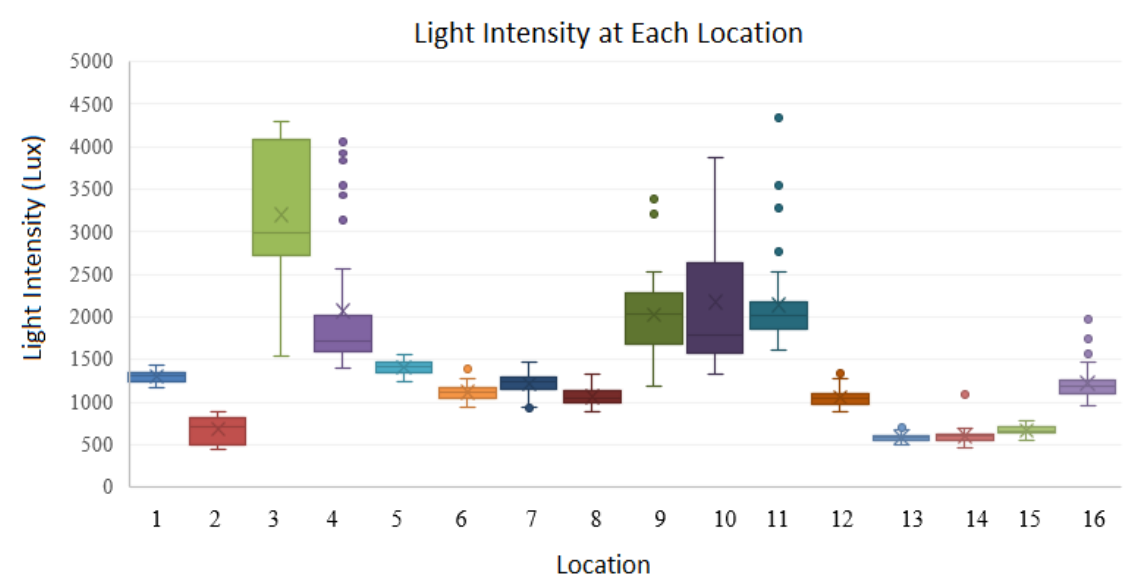

Figure 9. Light intensity boxplot

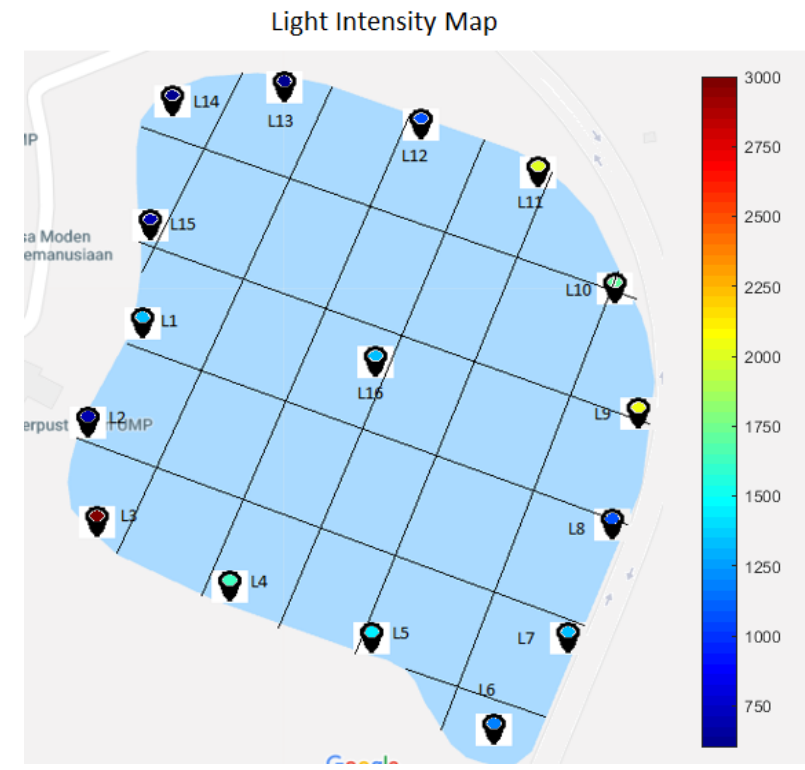

Figure 10. Light intensity map 


\section{4. $\mathrm{X}-\mathrm{Y}$ acceleration}

Figure 10 and 11 shows $\mathrm{x}$ and $\mathrm{y}$-axis acceleration respectively for every 16 locations. The data is collected with the x-axis accelerometer is pointed North and y-axis accelerometer is pointed East. With the aid of GPS, the use of IMU for collecting $x$ and $y$-axis acceleration data is for monitoring water movement. Referring to Figure 10, the value of $\mathrm{x}$-axis is varied from $-9.7 \mathrm{~m} / \mathrm{s}^{2}$ to $11 \mathrm{~m} / \mathrm{s}^{2}$. The wave and wind factor influenced the reading. Location L14, L15 and L16 shows the presence of outliers which is exceed to the lower limit and upper limit for box-plot. Large range of acceleration can be seen at location L16 which is situated in the middle of the lake. This may be due to excessive water agitation due to the rocking canoe.

Referring to Figure 11, the minimum and maximum y-axis acceleration for all locations is from- 8.8 $\mathrm{m} / \mathrm{s}^{2}$ to $4.5 \mathrm{~m} / \mathrm{s}^{2}$. Location L6 till L12 seems to be stagnant whereas location L16 shows large variation in acceleration. Similar to $\mathrm{x}$-axis acceleration, the $\mathrm{y}$-axis acceleration at location L16 may be due to excessive water agitation by rocking canoe. This can be resolved if the system where to be deployed and left until the rocking water has subdued before the data is collected. Both $\mathrm{x}$ and $\mathrm{y}$-axis mean acceleration data is plotted on the acceleration map and can be seen in Figure 13. Referring to Figure 13, the location which is near the bank has almost the same mean data whereas the highest mean acceleration data can be seen at the middle of the lake. The location of the testing may not be suitable for collecting acceleration data since all location is near the bank.

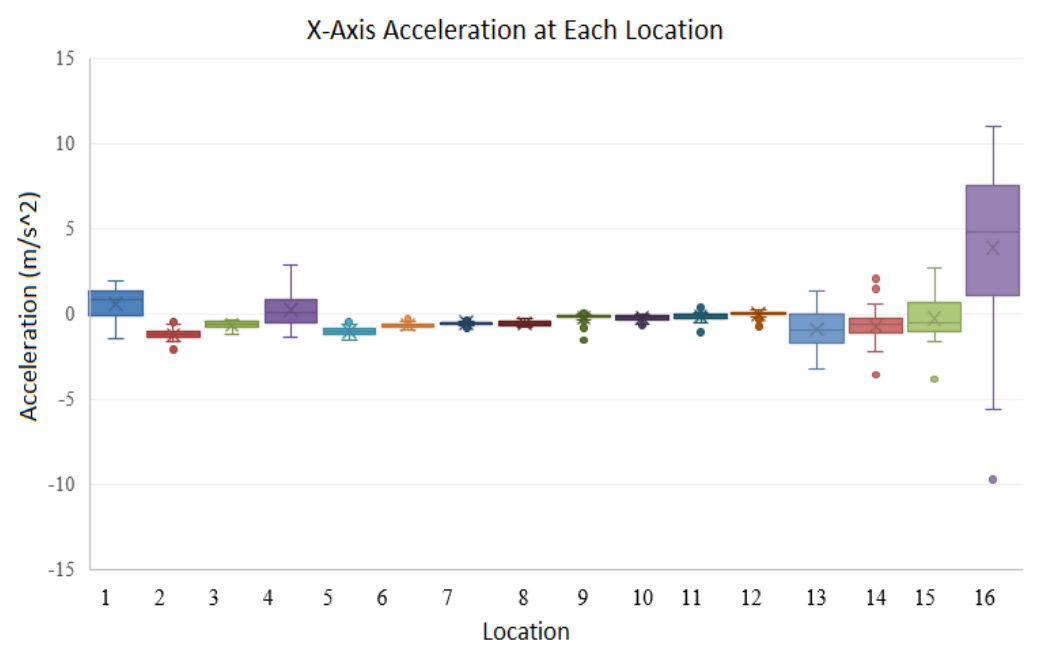

Figure 11. X-axis acceleration boxplot

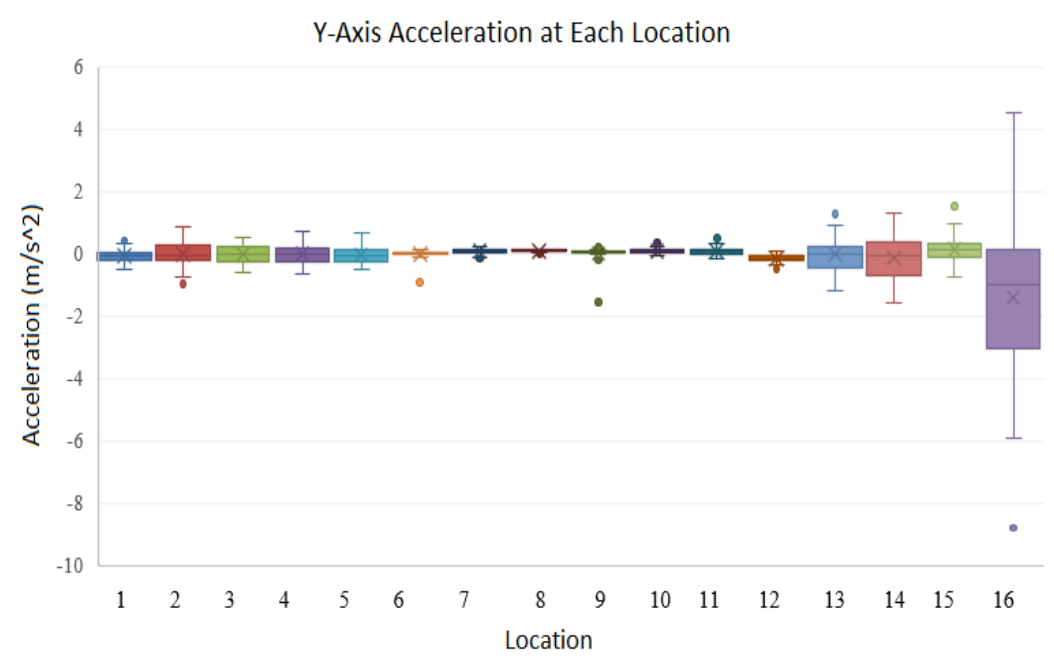

Figure 12. Y-axis acceleration boxplot 


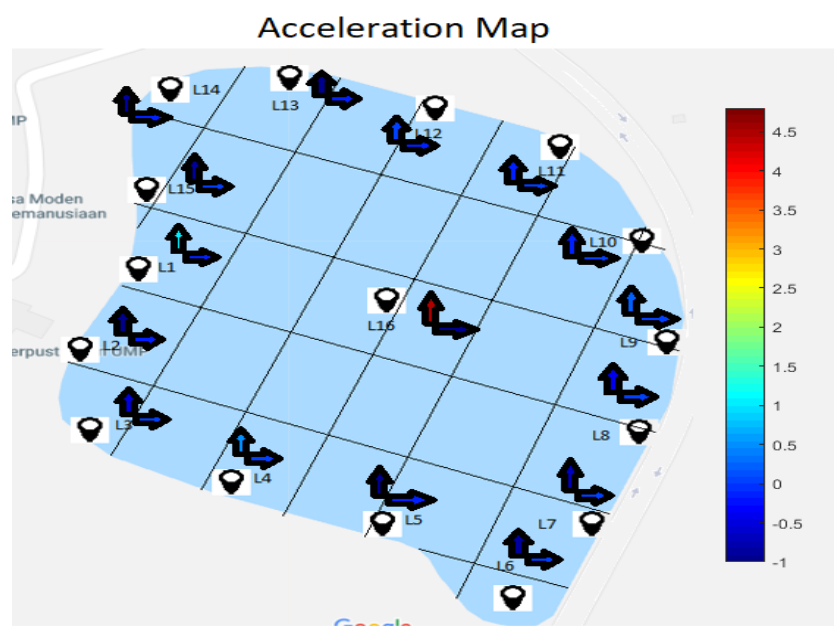

Figure 13. Acceleration map

\section{CONCLUSION}

The development of IoT based water quality catchment monitoring system has successfully collected data continuously in terms of acidity, temperature, light intensity, location and acceleration. All data has been plotted on the site map and it is evident that all data correlation between all locations can be clearly seen. X-Y axis acceleration data need to be processed further for it to be useful. The analysis data could be used to predict the pollution sources in the water by implementing prediction algorithm which will be done next in this research which will be discussed in future paper. The system is successfully developed but there is room for improvement.

\section{ACKNOWLEDGEMENTS}

The authors would like to thank Universiti Malaysia Pahang (UMP) for financing the research through final year student project fund and PNI research fund RDU1703315. The authors also would like to thank UMP for a permission to conduct an experiment at UMP's lake.

\section{REFERENCES}

[1] N. Vijayakumar and R. Ramya, “The Real Time Monitoring of Water Quality in IoT Environment," IEEE Spons. 2nd Int. Conf. Innov. Information,Embedded Commun. Syst. (ICIIECS), pp. 1-4, 2015.

[2] B. Das and P. C. Jain, "Real-Time Water Quality Monitoring System using Internet of Things" International Conference on Computer, Communications and Electronics (Comptelix), pp. 78-82, 2017.

[3] Ms. Ch.Sowmya, Dr. C.D.Naidu, Ddr.Rajendra Prasad, and D. Ramesh Reddy," Implementation of Wireless Sensor Network for Real Time Overhead Tank Water Quality Monitoring”,2017 IEEE 7th International Advance Computing Conference,pg(s):546-551

[4] Nahla Abdul Jalil Salih, Ihsan Jabbar Hasan, Nadhir Ibrahim Abdulkhaleq, "Design and implementation of a smart monitoring system for water quality of fish farms", Indonesian Journal of Electrical Engineering and Computer Science, Vol. 14, No. 1, pp. 44-50, April 2019.

[5] C. Z. Myint, L. Gopal, and Y. L. Aung, "Reconfigurable smart water quality monitoring system in IoT environment," 16th IEEE/ACIS Int. Conf. Comput. Inf. Sci. ICIS 2017, pp. 435-440, 2017.

[6] A.N.Prasad, K. A. Mamun, F. R. Islam, and H.Haqva, "Smart water quality monitoring system," 2nd Asia-Pacific World Congr. Comput. Sci. Eng. APWC CSE 2015, pp. 1-6, 2015.

[7] A. A. Pranata, J. M. Lee, and D. S. Kim, "Towards an IoT-based Water Quality Monitoring System with Brokerless Pub / Sub Architecture," IEEE International Symposium on Local and Metropolitan Area Networks (LANMAN), 2017.

[8] T. I. Salim, H. S. Alam, R. P. Pratama, I. Asfy, F. Anto, and A. Munandar, "Portable and Online Water Quality Monitoring System using Wireless Sensor Network," 2nd International Conference on Automation, Cognitive Science, Optics, Micro Electro-Mechanical System, and Information Technology (ICACOMIT), pp. 34-40, 2017.

[9] A. Latiff and S. K. Syed-, "Wireless Water Quality Cloud Monitoring System with Self-healing Algorithm," IEEE 13th Malaysia International Conference on Communications (MICC), pp. 28-30, 2017.

[10] Cho Zin Myint, Lenin Gopal, and Yan Lin Aung, "WSN-based reconfigurable water quality monitoring system in IoT environment," 14th International Conference on Electrical Engineering/Electronics, Computer, Telecommunications and Information Technology (ECTI-CON), pg(s): 741-744. 
[11] Kamarul Hafiz Kamaludin and Wildad Ismail, "Water Quality Monitoring With Internet of Things ( IoT )," 2017 IEEE Conference on Systems, Process and Control (ICSPC), 15-17 December 2017, Melaka, Malaysia, 2017.

[12] C. Encinas, E. Ruiz, J. Cortez, and A. Espinoza, "Design and implementation of a distributed IoT system for the monitoring of water quality in aquaculture," Wireless Telecommunications Symposium (WTS), pp. 1-7, 2017.

[13] T. P. Lambrou, C. C. Anastasiou, C. G. Panayiotou and M. M. Polycarpou, "A Low-Cost Sensor Network for RealTime Monitoring and Contamination Detection in Drinking Water Distribution Systems," in IEEE Sensors Journal, vol. 14, no. 8, pp. 2765-2772, Aug. 2014.

[14] M. A. Miskam, I. A. Rahim, O. Sidek, M. Q. Omar and M. Z. Ishak, "Deployment of wireless water-quality monitoring system at titi serong paddy crop field, Malaysia," 2013 IEEE 3rd International Conference on System Engineering and Technology, Shah Alam, 2013, pp. 57-60.

[15] K. R. S. R. Raju and G. H. K. Varma, "Knowledge Based Real Time Monitoring System for Aquaculture Using IoT," 2017 IEEE 7th International Advance Computing Conference (IACC), Hyderabad, 2017, pp. 318-321.

[16] G. S. Menon, M. V. Ramesh and P. Divya, "A low cost wireless sensor network for water quality monitoring in natural water bodies," 2017 IEEE Global Humanitarian Technology Conference (GHTC), San Jose, CA, 2017, pp. $1-8$.

[17] T. Kageyama, M. Miura, A. Maeda, A. Mori and S. Lee, "A wireless sensor network platform for water quality monitoring," 2016 IEEE SENSORS, Orlando, FL, 2016, pp. 1-3.

[18] Kulkarni Amruta M. and Turkane Satish M., "Solar Powered Water Quality Monitoring system using wireless Sensor Network", International Mutli-Conference on Automation, Computing, Communication, Control and Compressed Sensing (iMac4s), pp: 281-285.

[19] Khetre, A. C., \& Hate, S. G., "Automatic monitoring \& reporting of water quality by using WSN technology and different routing methods". International Journal of Advanced Research in Computer Engineering \& Technology, 2(12), 3255-3260, 2013

[20] Nidal Nasser, Asmaa Ali, Lutful Karim, Samir Belhaouari, “An Efficient Wireless Sensor Network-based Water Quality Monitoring System", ACS International Conference on Computer Systems and Applications (AICCSA), 2013.

[21] S. Noorjannah Ibrahim, A. L. Asnawi, N. Abdul Malik, N. F. Mohd Azmin, A. Z. Jusoh, F. N. Mohd Isa, "Web based Water Turbidity Monitoring and Automated Filtration System: IoT Application in Water Management", International Journal of Electrical and Computer Engineering (IJECE), Vol. 8, No. 4, August 2018, pp. 2503 2511.

[22] F. R. Islam and K. A. Mamun, "GIS based Water Quality Monitoring System in Pacific Coastal Area: A Case Study For Fiji”, 2nd Asia-Pacific World Congress on Computer Science and Engineering (APWC on CSE), 2015.

[23] He, D., \& Zhang, L.-X., "The water quality monitoring system based on WSN", 2nd international conference on consumer electronics, communications and networks (CECNet), pp. 3661-3664, 2012.

[24] Rasin, Z., \& Abdullah, M. R., "Water quality monitoring system using zigbee based wireless sensor network". International Journal of Engineering \& Technology, 9(10), 14-18, 2009.

[25] Muhammad Aznil Ab Aziz, M. F. Abas, A. A. N. Faudzi, N. Md. Saad, A Irawan, "Development of Wireless Passive Water Quality Catchment Monitoring System", Journal of Telecommunication, Electronic and Computer Engineering, Vol. 10, No 1-3,pg(s): 37-40 (2018). 